\title{
Assessment of global left ventricular function and volumes with 320-row multidetector computed tomography: A comparison with 2D-echocardiography
}

\author{
Fleur R. de Graaf, MD, ${ }^{a}$ Joanne D. Schuijf, PhD, ${ }^{a}$ Joëlla E. van Velzen, $M D,{ }^{a, b}$ \\ Gaetano Nucifora, MD, ${ }^{a}$ Lucia J. Kroft, $M D, P h D,{ }^{c}$ Albert de Roos, MD, PhD, ${ }^{c}$ \\ Martin J. Schalij, MD, PhD, ${ }^{a} J$. Wouter Jukema, $M D, P h D,{ }^{a, b}$ Ernst E. van der Wall, \\ $M D, P h D,{ }^{a, b}$ and Jeroen J. Bax, MD, PhD ${ }^{a}$
}

Background. Multidetector computed tomography (MDCT) has been demonstrated as a feasible imaging modality for noninvasive assessment of coronary artery disease and left ventricular (LV) function. Recently, 320-row systems have become available with $16 \mathrm{~cm}$ anatomical coverage allowing image acquisition of the entire heart within a single heartbeat. The purpose of this study was to evaluate the accuracy of 320-row MDCT in the assessment of global LV function compared to two-dimensional (2D) echocardiography as the standard of reference.

Methods and Results. A head-to-head comparison between 320-row MDCT and 2D-echocardiography was performed in 114 patients $(68$ men; mean age $62 \pm 13$ years) who were clinically referred for MDCT coronary angiography. The entire heart was imaged in a single heartbeat, using prospective dose modulation. LV end-diastolic volumes (LVEDV) and LV endsystolic volumes (LVESV) were determined and the LV ejection fraction (LVEF) was derived. Average LVEF was $60 \pm 10 \%$ (range 26-78\%) as determined on MDCT, compared with $59 \pm 10 \%$ (range $25-77 \%$ ) on 2D-echocardiography. Evaluation of LVEF by linear regression analysis showed a good correlation between MDCT and 2D-echocardiography $\left(r^{2}=.87\right.$; $P<.001)$. Good correlations between MDCT and 2D-echocardiography were demonstrated for the assessment of LVEDV $\left(r^{2}=.91 ; P<.001\right)$ and LVESV $\left(r^{2}=.94 ; P<.001\right)$. At BlandAltman analysis, mean differences $( \pm$ SD $)$ of $7.3 \pm 12.1 \mathrm{~mL}(P<.05)$ and $1.8 \pm 7.4 \mathrm{~mL}(P<.05)$ were observed between MDCT and 2D-echocardiography for LVEDV and LVESV, respectively. LVEF was slightly overestimated with MDCT $(.9 \pm 3.6 \% ; P<.05)$.

Conclusions. Accurate assessment of $\mathrm{LV}$ function and volumes is feasible with single heartbeat 320-row MDCT in patients referred for MDCT coronary angiography. ( $J$ Nucl Cardiol 2010;17:225-31.)

Key Words: Multidetector computed tomography $\bullet$ left ventricular function $\cdot$ cardiac imaging

From the Department of Cardiology, ${ }^{\text {a }}$ Leiden University Medical Center, Leiden, The Netherlands; The Interuniversity Cardiology Institute of the Netherlands, ${ }^{\mathrm{b}}$ Utrecht, The Netherlands; Department of Radiology, ${ }^{\mathrm{c}}$ Leiden University Medical Center, Leiden, The Netherlands.

Dr. de Graaf is co-supported by the Dutch Technology Foundation STW (Utrecht, the Netherlands), applied science division of NWO and the Technology Program of the Ministry of Economic Affairs, grant nr. 10084. Dr. van Velzen is supported by the Netherlands Heart Foundation (The Hague, The Netherlands), grant nr. 2007B223. Dr. Nucifora is supported by a grant from the European Association of Percutaneous Cardiovascular Interventions. Dr. Schalij has research grants from Boston Scientific (Natick, United States), Medtronic (Minneapolis, United States) and Biotronik (Berlin, Germany). Dr. Bax has research grants from Medtronic
(Minneapolis, United States), Boston Scientific (Natick, United States), BMS medical imaging (New York, United States), St. Jude Medical (St. Paul, United States), GE Healthcare (Chalfont St. Giles, United Kingdom), Biotronik (Berlin, Germany), and Edwards Lifesciences (Irvine, United States).

Received for publication Jul 2, 2009; final revision accepted Nov 13, 2009.

Reprint requests: Jeroen J. Bax, MD, PhD, Department of Cardiology, Leiden University Medical Center, Postal Zone: C5-P, P.O. Box 9600, 2333 ZA, Leiden, The Netherlands; j.j.bax@lumc.nl. $1071-3581 / \$ 34.00$

Copyright (C) 2009 The Author(s). This article is published with open access at Springerlink.com doi:10.1007/s12350-009-9173-y 


\section{INTRODUCTION}

The assessment of global left ventricular (LV) function and volumes is important in patients with coronary artery disease (CAD) and serves as a valuable diagnostic and prognostic marker. ${ }^{1,2}$ There are several noninvasive imaging modalities to analyze cardiac function, which include two-dimensional (2D)-echocardiography, ${ }^{3}$ single photon emission computed tomography (SPECT) ${ }^{4}$ and cardiac magnetic resonance imaging (MRI). ${ }^{5}$

In recent years, multidetector computed tomography (MDCT) has emerged as a rapidly advancing imaging modality for the noninvasive assessment of CAD. Since the introduction of MDCT in the early 1990s, acquisition times, spatial and temporal resolution have continuously improved resulting in excellent image quality and diagnostic accuracy in the detection of CAD. ${ }^{6}$ Furthermore, various studies have shown that accurate simultaneous assessment of $\mathrm{CAD}$ and $\mathrm{LV}$ function is feasible. ${ }^{7-13}$ Accurate evaluation of cardiac function and volumes with MDCT, in addition to noninvasive assessment of the coronary arteries is likely to optimize the clinical evaluation of patients with CAD. ${ }^{14}$

Previous 4-, 16- and 64-row MDCT systems used a helical scanning technique with retrospective ECG gating. These systems covered the entire heart in multiple heartbeats, which involved a considerable risk of motion artifacts due to arrhythmias and breathing. With the recent introduction of 320-row MDCT, a cylindrical volumetric dataset covering the entire heart is acquired within a single rotation or heartbeat. This technology, in combination with prospective ECG gating, markedly reduces scan time and contrast administration, while at the same time reducing motion artifacts. In addition, 320-row MDCT has a reduced gantry rotation time with improved temporal resolution.

The accuracy of 320-row MDCT for the evaluation of LV function and volumes has not been reported. The purpose of this study therefore was to evaluate the accuracy of 320-row MDCT in the assessment of global $\mathrm{LV}$ function compared to 2D-echocardiography as the standard of reference.

\section{MATERIALS AND METHODS}

\section{Patients and Study Protocol}

The study group consisted of 114 patients who were clinically referred for MDCT coronary angiography to evaluate the presence and extent of CAD. All patients were consecutively enrolled and prospectively included in the study. All patients underwent 320-row cardiac MDCT. Exclusion criteria were: (1) (supra)ventricular arrhythmias, (2) renal insufficiency (glomerular filtration rate $<30 \mathrm{~mL} / \mathrm{min}$ ), (3) known
Table 1. Clinical characteristics of the study population

\begin{tabular}{ll}
\hline Number of patients & 114 \\
Age (years) & $62 \pm 13$ \\
Men/women & $68 / 46$ \\
Body mass index $\left(\mathrm{kg} / \mathrm{m}^{2}\right)$ & $27 \pm 4$ \\
Family history of coronary artery disease & $40(35 \%)$ \\
Diabetes & $28(25 \%)$ \\
Hypertension & $78(68 \%)$ \\
Hypercholesterolemia & $54(47 \%)$ \\
$\begin{array}{l}\text { Current smoker } \\
\text { Previous myocardial infarction }\end{array}$ & $17(15 \%)$ \\
Location & $9(8 \%)$ \\
$\quad \begin{array}{l}\text { Anterior } \\
\text { Inferior }\end{array}$ & $2(2 \%)$ \\
Previous percutaneous coronary & $7(6 \%)$ \\
$\quad$ intervention & $16(14 \%)$ \\
Previous coronary artery bypass grafting & $9(8 \%)$ \\
Pacemaker or implantable cardioverter & $6(5 \%)$ \\
$\quad$ defibrillator &
\end{tabular}

allergy to iodine contrast material, (4) severe claustrophobia, and (5) pregnancy. The study population consisted of $68 \mathrm{men}$ and 46 women, with a mean age of $62 \pm 13$ years. The main clinical characteristics of the study population are listed in Table 1. LV volumes and LV ejection fraction (LVEF) were assessed and compared with 2D-echocardiography. MDCT and 2D-echocardiography were performed within 3 months of each other. In 21 patients, both examinations were performed on the same day. No cardiac events occurred between examinations.

\section{MDCT}

Data acquisition. MDCT studies were performed using a 320-row MDCT scanner (Aquilion ONE, Toshiba Medical Systems, Otawara, Japan) with 320 detector rows (each $.5 \mathrm{~mm}$ wide) and a rotation time of $350 \mathrm{~ms}$ (with a temporal resolution of $175 \mathrm{~ms}$ for half reconstruction). Unless contraindicated, beta-blocker was administered orally (50$100 \mathrm{mg}$ metoprolol depending on heart rate) 1 hour before data acquisition to patients with a heart rate exceeding 65 beats per minute (bpm) to reduce cardiac motion artifacts. During the MDCT examination, the average heart rate \pm standard deviation (SD) was $57 \pm 9$ bpm.

The entire heart was imaged in a single heartbeat, using prospective dose modulation attaining maximal tube current during $65-85 \%$ of $\mathrm{R}-\mathrm{R}$ interval (in patients with a heart rate $\geq 60 \mathrm{bpm}$ ), or during $75 \%$ of $\mathrm{R}-\mathrm{R}$ interval (in patients with stable heart rate $<60 \mathrm{bpm}$ ). Outside the predefined interval, tube current was $25 \%$ of the maximal tube current. In addition, at the start of the R-R interval image acquisition was performed at maximal tube current. Six patients had a heart rate $>65 \mathrm{bpm}$ and in these patients images were acquired during multiple heartbeats (typically two). Tube voltage and 
tube current were adapted to body weight and thoracic anatomy. Tube voltage was $100 \mathrm{kV}(n=4), 120 \mathrm{kV}(n=109)$, or $135 \mathrm{kV}(n=1)$. Tube voltage was adapted to $135 \mathrm{kV}$ in patients with a body mass index $>35 \mathrm{~kg} / \mathrm{m}^{2}$. Maximal tube current was $400 \mathrm{~mA} \quad(n=5), 450 \mathrm{~mA} \quad(n=7), 480 \mathrm{~mA}$ $(n=2), 500 \mathrm{~mA} \quad(n=61), 550 \mathrm{~mA} \quad(n=3)$, or $580 \mathrm{~mA}$ $(n=36)$. A tri-phasic injection of intravenous contrast was used and the total amount of nonionic contrast media (Iomeron 400; Bracco, Milan, Italy) injected into the antecubital vein was $60-70 \mathrm{~mL}$ (depending on body weight). First, 50-60 mL of contrast media was administered at a flow rate of 5.0 or $6.0 \mathrm{~mL} / \mathrm{s}$, followed by $20 \mathrm{~mL}$ of $50 \%$ contrast/saline. Subsequently a saline flush of $25 \mathrm{~mL}$ was administered at a flow rate of $3.0 \mathrm{~mL} / \mathrm{s}$. In order to synchronize the arrival of the contrast media and the scan, bolus arrival was detected using automated peak enhancement detection in the LV. After the preset contrast enhancement threshold of baseline Hounsfield units $(\mathrm{HU})+100 \mathrm{HU}$ was reached, the MDCT examination was automatically initiated. After a two second delay, images were acquired during an inspiratory breath hold of approximately 5 seconds. During the scan, the ECG was registered simultaneously for prospective gating of the data. Average estimated radiation exposure $( \pm \mathrm{SD})$ during a single examination was $11.5 \pm 2.1 \mathrm{mSv}$. Radiation dose was quantified with a doselength product conversion factor of $.014 \mathrm{mSv} /(\mathrm{mGy} \times \mathrm{cm})$ as described. ${ }^{15}$ MDCT was performed successfully in all patients without complications. The average investigation time for the MDCT acquisitions was approximately 20 minutes.

Data analysis. To assess LV function and LV volumes, 10 series of $2.0-\mathrm{mm}$ slices were reconstructed in the short-axis orientation at every $10 \%$ throughout the cardiac cycle, starting at early systole ( $0 \%$ of cardiac cycle) to enddiastole ( $90 \%$ of cardiac cycle). Subsequently, images were transferred to a remote workstation with dedicated cardiac function analysis software (Vitrea FX 1.0, Vital Images, Minnetonka, MN, USA). To acquire the appropriate phases for LV end-systolic volume (LVESV) and LV end-diastolic volume (LVEDV), the smallest and largest cross-sectional LV cavity areas were selected, respectively. Upper limit of the LV was determined at the basal level of the mitral valve and the start of the LV outflow tract. Endocardial borders were semiautomatically outlined from the base to the apex on the shortaxis cine images by an independent observer. Papillary muscles were excluded from the ventricular cavity. The LVEDV and LVESV volumes were calculated, and the LVEF was derived by subtracting the LVESV from the LVEDV and dividing the result by the LVEDV. Time to reconstruct the required image sets and calculate LV volumes and LVEF was approximately 10 minutes. Inter-observer agreement of LV volume and function analyses was analyzed with repeated measurements of a second experienced independent observer in 13 randomly selected patients.

2D-echocardiography. For comparison of LVEF and LV volumes, 2D-echocardiography was performed to serve as the standard of reference. All patients were imaged in left lateral decubital position with a commercially available system (Vivid 7 Dimension, GE Healthcare, Horten, Norway) equipped with a $3.5-\mathrm{MHz}$ transducer. Images were obtained in the standard 4- and 2-chamber apical views and were saved in cine-loop format. Analyses were subsequently performed offline using EchoPAC version 7.0.0 (GE Healthcare, Horten, Norway) by a cardiologist, with 10 years of experience, blinded to MDCT data. LVEDV and LVESV volumes were measured according to the Simpson's biplane method ${ }^{16}$ and LVEF was derived.

Statistical analysis. Continuous data were expressed as mean \pm SD and compared using the paired two-tailed Student's $t$ test. Agreement for the LV volumes and function by MDCT and echocardiography were determined by Pearson's correlation coefficient for linear regression and BlandAltman analysis. The $95 \%$ limits of agreement were defined as the range of values \pm 2 SDs from the mean value of the differences. A $P$ value $<.05$ was considered statistically significant. To determine inter-observer agreement, intra-class correlation coefficients were used as indicators of reproducibility. Good agreement was defined as intra-class correlation coefficients $>.80$.

\section{RESULTS}

\section{LVEDV}

Average LVEDV was $146 \pm 40 \mathrm{~mL}$ (range 78$278 \mathrm{~mL}$ ) on MDCT, as compared with $139 \pm 40 \mathrm{~mL}$ (range $72-269 \mathrm{~mL}$ ) on 2D-echocardiography. Linear regression analysis showed a good correlation between MDCT and 2D-echocardiography for the assessment of LVEDV $\left(r^{2}=.91 ; P<.001\right)$ (Figure 1A). At BlandAltman analysis, mean differences $( \pm \mathrm{SD})$ of $7.3 \pm$ $12.1 \mathrm{~mL}(P<.05)$ were observed between MDCT and 2D-echocardiography, with $95 \%$ limits of agreement ranging from -16.5 to 31.1 (Figure $1 \mathrm{~B}$ ).

\section{LVESV}

On MDCT, average LVESV was $61 \pm 30 \mathrm{~mL}$ (range $17-195 \mathrm{~mL}$ ), as compared with $59 \pm 29 \mathrm{~mL}$ (range 18$183 \mathrm{~mL}$ ) on 2D-echocardiography. The correlation coefficient between the two modalities for the assessment of LVESV was good $\left(r^{2}=.94 ; P<.001\right)$ (Figure 2A). Bland-Altman analysis showed a mean value of difference $( \pm \mathrm{SD})$ of $1.8 \pm 7.4 \mathrm{~mL}(P<.05)$ between MDCT and 2D-echocardiography. The $95 \%$ limits of agreement ranged from -12.7 to 16.2 (Figure $2 \mathrm{~B}$ ).

\section{LVEF}

Average LVEF was $60 \pm 10 \%$ (range 26-78\%) as determined on MDCT, compared with $59 \pm 10 \%$ (range $25-77 \%$ ) on 2D-echocardiography. Evaluation of LVEF by linear regression analysis demonstrated a good correlation between MDCT and 2D-echocardiography $\left(r^{2}=.87 ; P<.001\right)$ (Figure 3A). At Bland-Altman 

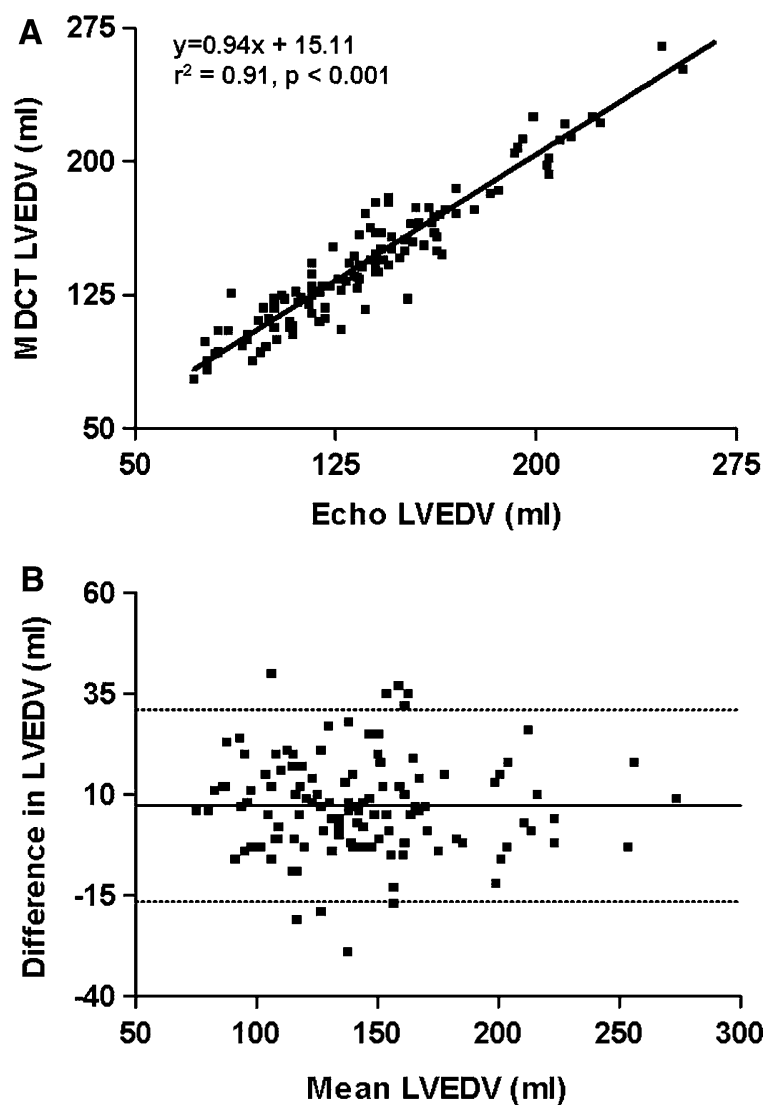

Figure 1. Comparison of MDCT and 2D-echocardiography in the assessment of LVEDV. Linear regression plot shows the correlation between LVEDV as measured by MDCT and 2Dechocardiography (A). Bland-Altman plot of LVEDV shows the difference between each pair plotted against the average value of the same pair (solid line, mean value of difference; dotted line, mean value of differences \pm 2 SDs) (B). LVEDV, Left ventricular end-diastolic volume; $M D C T$, multidetector computed tomography.

analysis, LVEF was slightly overestimated with MDCT $(.9 \pm 3.6 \% ; P<.05)$ (Figure 3B).

The inter-observer agreement for LVEDV, LVESV, and LVEF, measured by intra-class correlation, were $.98, .97$, and .92 , respectively.

\section{DISCUSSION}

In this study, the accuracy of single heartbeat 320row MDCT in the assessment of global cardiac function was evaluated in patients clinically referred for MDCT coronary angiography. 2D-echocardiography served as the standard of reference.

This study demonstrates that evaluation of LV volumes and global LV function is feasible with single heartbeat 320-row MDCT in patients clinically referred for MDCT coronary angiography. Excellent correlations were observed between MDCT and 2D-echocardiography
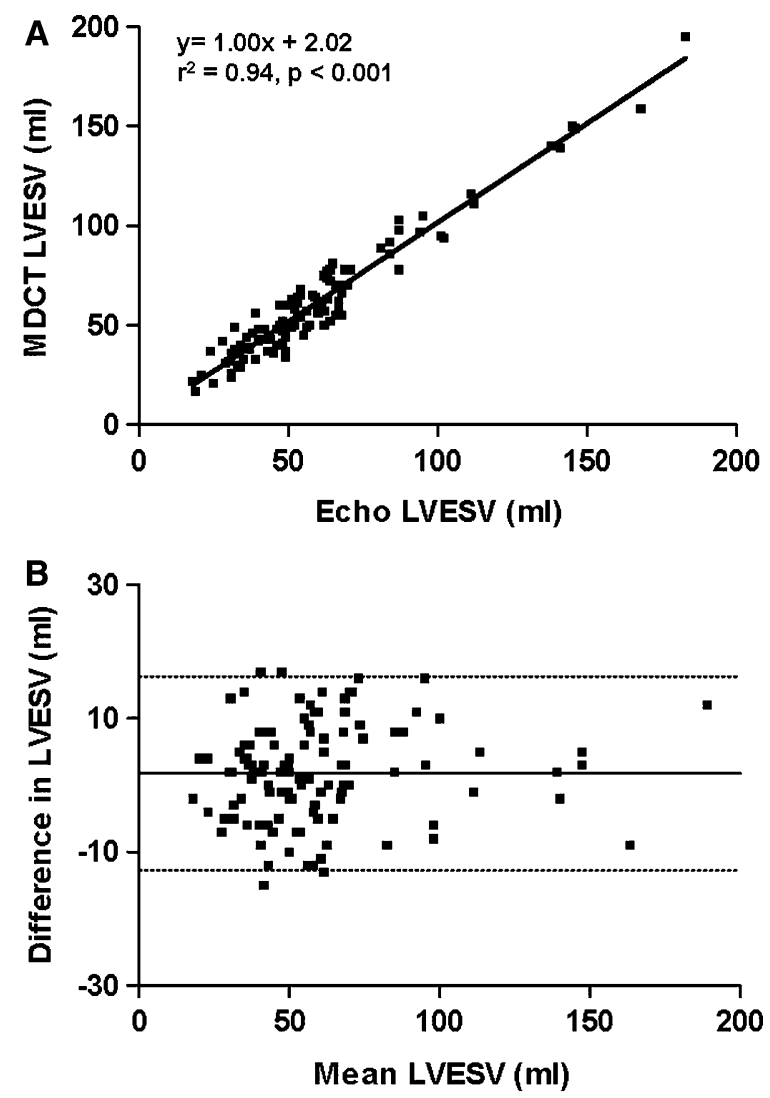

Figure 2. Comparison of MDCT and 2D-echocardiography in the assessment of LVESV. Linear regression plot shows the correlation between LVESV as measured by MDCT and 2Dechocardiography (A). In a Bland-Altman plot of LVESV, the difference between each pair plotted against the average value of the same pair is shown (solid line, mean value of difference; dotted line, mean value of differences \pm 2 SDs) (B). LVESV, Left ventricular end-systolic volume; $M D C T$, multidetector computed tomography.

for LVEDV $\left(r^{2}=.91 ; P<.001\right)$ and $\operatorname{LVESV}\left(r^{2}=.94\right.$; $P<.001)$. Minor overestimations for LVESV and LVEDV of 1.8 and $7.3 \mathrm{~mL}$, respectively, were observed on MDCT. Consequently, LVEF measured by MDCT yielded a slight overestimation of .9\% compared with 2Dechocardiography.

\section{Comparison with Previous Studies}

The results of this study are in-line with results of previous MDCT studies. ${ }^{7-13}$ In a prior study conducted by Kim et al, ${ }^{9}$ a good agreement was demonstrated for LVEF, as determined by 16-row MDCT and 2D-echocardiography $(r=.86 ; P<.001)$. Similar to our study, a slight overestimation of $2.9 \%$ using MDCT was shown. More recently, global LV function was investigated by $\mathrm{Wu}$ et $\mathrm{al}^{13}$ using 64-row MDCT and 2Dechocardiography. The investigators showed a good 

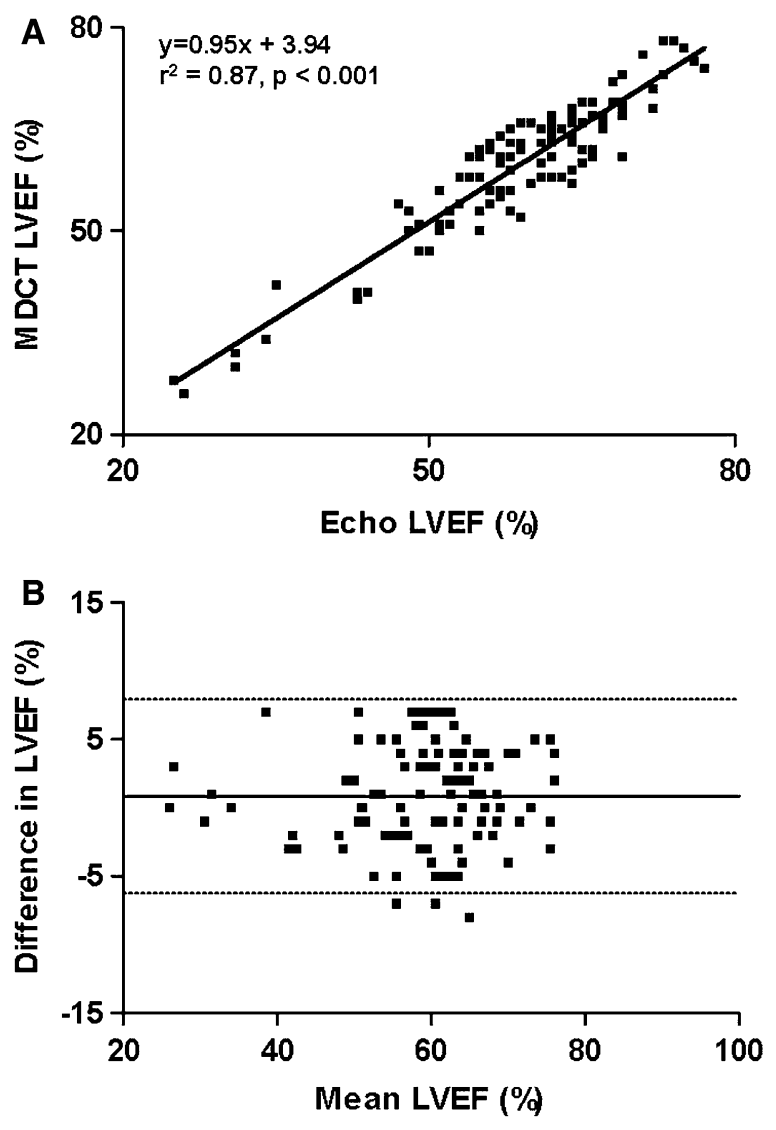

Figure 3. Comparison of MDCT and 2D-echocardiography in the assessment of LVEF. Linear regression plot comparing MDCT and 2D-echocardiography in the assessment of LVEF (A). Bland-Altman plot of LVEF shows the difference between each pair plotted against the average value of the same pair (solid line, mean value of difference; dotted line, mean value of differences \pm 2 SDs) (B). LVEF, Left ventricular ejection fraction; $M D C T$, multidetector computed tomography.

correlation between the two imaging modalities for the assessment of LVEF $(r=.87, P<.001)$. However, also with 64-row MDCT, systematic overestimation of LVEF has been reported. ${ }^{12}$ Accordingly, the results of this study using 320-row MDCT technology appear to be in agreement with prior results using 16- and 64-row MDCT. Possibly, assessment with 320-row MDCT may even be more closely related to 2D-echocardiography as compared to older MDCT generations due to the fact that data are acquired in a single heartbeat rather than during multiple heartbeats.

\section{Overestimation LV Volumes by MDCT}

In this study, a slight overestimation of LV volumes by MDCT was observed as compared with 2D-echocardiography. A factor that might contribute to the overestimation in LV volumes by 320-row MDCT is the use of dose modulation. While this feature has become available as a means to reduce radiation exposure to the patient as compared to full-dose scanning, it is associated with a slight decrease in image quality in images acquired during decreased tube current (Figure 4). However, it is unlikely that this minor decrease in image quality would have affected global LV volume measurements. Second, discrepancies may be explained by differences in the definition of the upper limits of the ventricle, which can be set at different levels depending on the technique used. Currently, there are no clear guidelines on the systematic analysis of MDCT data for the purpose of cardiac function assessment. Finally, the minor overestimation of LV volumes by MDCT as compared to 2D-echocardiography may be explained by the different approach of $\mathrm{LV}$ volume calculation between the two techniques. While 2D-echocardiography is most routinely used to measure cardiac function in daily clinical practice, its main limitation remains that measurements are based on a geometric assumption of $2 \mathrm{D}$ images. As a result, inaccuracies in volumetric calculations may occur. In contrast, MDCT allows endocardial border definition with high-resolution using true 3D reconstructions. Yamamuro et al recently showed that measurements between MDCT and MRI, the current gold standard for LV function assessment, were more closely related as compared to measurements between 2D-echocardiography and MRI. ${ }^{17}$ MDCT may therefore be a more accurate tool for LV function analysis than 2D-echocardiography, and this may explain the small differences in LV volumes between the two techniques.

\section{Study Limitations}

Although assessment of cardiac function is feasible with 320-row MDCT, several limitations should be addressed. First, the main limitation of the current study is the lack of a true gold standard such as cardiac MRI. Cardiac MRI has long been regarded as the gold standard in noninvasive analysis of $\mathrm{LV}$ function. ${ }^{18}$ Importantly, many studies have previously shown excellent correlations between MDCT and MRI in the assessment of LVEF and LV volumes. ${ }^{17,19,20}$ Accordingly, in order to further validate the performance of 320-row MDCT for the assessment of LV volumes and function, a direct comparison between 320-row MDCT and MRI is desirable. Second, in patients with a heart rate $>65 \mathrm{bpm}$ additional beta-blocking medication was administered prior to MDCT investigation, but not before 2D-echocardiography. A potential bias may have been introduced by the administration of beta-blockade immediately prior to MDCT examination, ${ }^{21}$ as well as the use of contrast agents at the time of MDCT, as these 

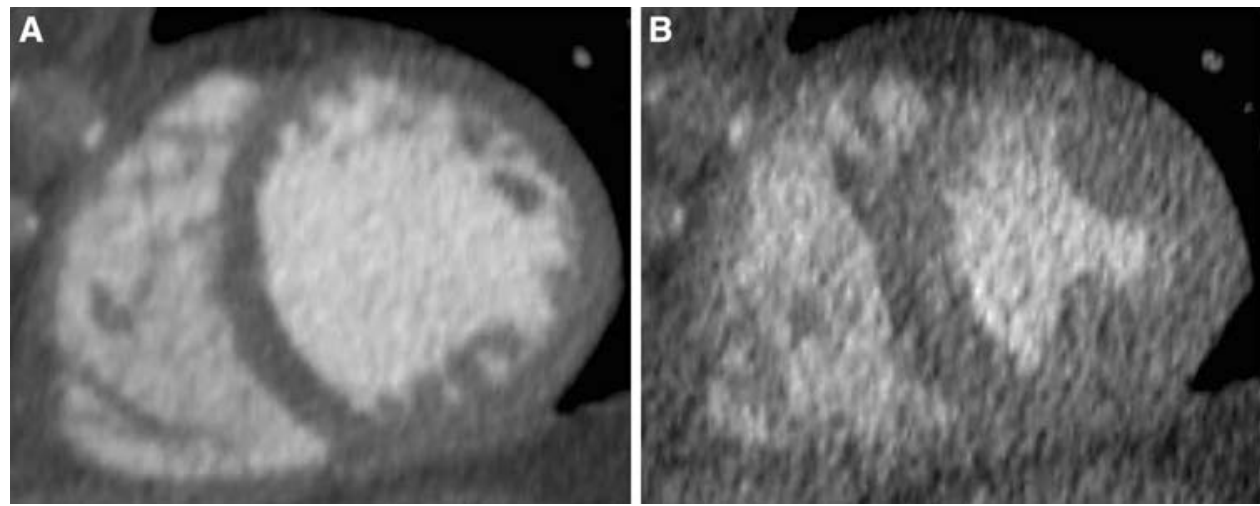

Figure 4. Example of 320-row MDCT image acquisition using dose modulation. Short-axis view of the left ventricle during end-diastolic phase (A) and end-systolic phase (B), acquired with 320row MDCT using dose modulation. To reduce radiation dose, image acquisition was performed using dose modulation, attaining maximal tube current at $75 \%$ of the R-R interval. Of note, at the start of the R-R interval image acquisition was still performed at maximal tube current. Outside the predefined interval and the first portion of the R-R interval, tube current was $25 \%$ of the maximal tube current. As a result, the end-diastolic phase (typically $0 \%$ ) still has good image quality whereas an increase in image noise in the end-systolic phase was observed. Additional scan parameters were: $120 \mathrm{kV}$ and $580 \mathrm{~mA}$ at maximal tube current. MDCT, Multidetector computed tomography.

pharmacological interventions may have affected LV volumes and LVEF. Third, a disadvantage of MDCT in general is the radiation exposure to the patient. Previously, information for LV function analysis could be derived retrospectively from the dataset acquired for the noninvasive evaluation of the coronary arteries. ${ }^{12}$ Recently, prospective ECG gating has become possible, allowing data-acquisition for MDCT coronary angiography during only a small proportion of the cardiac cycle. Since assessment of LV function requires dataacquisition during an entire cardiac cycle, in systems employing prospective ECG gating, including 320-row MDCT, functional analysis extends total exposure time. Consequently, the assessment of LV function by MDCT increases the radiation dose when compared to MDCT analysis for the purpose of coronary angiography alone. The necessity for LV function analysis should therefore be carefully considered for each individual patient. Importantly, lower mean radiation doses may be achieved with more optimal heart rate reduction, e.g., by using intravenous beta-blockade, which allows scanning at $75 \%$ of R-R interval in a larger proportion of patients. Furthermore, although the current population was scanned at $16 \mathrm{~cm}$ cranio-caudal scan-range, 320-row MDCT allows scanning of smaller ranges, which also decreases radiation exposure. In addition, only few patients with an LVEF lower than 50\% were included. As a result, the study is limited by the inclusion of a relatively homogeneous population with predominantly normal LV function. Further research is warranted to determine the accuracy of this technique in patients with low LVEF. Additionally, the time difference between
2D-echocardiography and MDCT may limit accurate comparison. Finally, as almost all patients were scanned during a single heartbeat, the current results predominantly reflect the evaluation of LV function using halfscan reconstructions.

\section{Open Access}

This article is distributed under the terms of the Creative Commons Attribution Noncommercial License which permits any noncommercial use, distribution, and reproduction in any medium, provided the original author(s) and source are credited.

\section{References}

1. Emond M, Mock MB, Davis KB, Fisher LD, Holmes DR Jr, Chaitman BR, et al. Long-term survival of medically treated patients in the Coronary Artery Surgery Study (CASS) Registry. Circulation 1994;90:2645-57.

2. Hofmann T, Meinertz T, Kasper W, Geibel A, Zehender M, Hohnloser $\mathrm{S}$, et al. Mode of death in idiopathic dilated cardiomyopathy: A multivariate analysis of prognostic determinants. Am Heart J 1988;116:1455-63.

3. Starling MR, Crawford MH, Sorensen SG, Levi B, Richards KL, O'Rourke RA. Comparative accuracy of apical biplane crosssectional echocardiography and gated equilibrium radionuclide angiography for estimating left ventricular size and performance. Circulation 1981;63:1075-84.

4. Vourvouri EC, Poldermans D, Bax JJ, Sianos G, Sozzi FB, Schinkel AF, et al. Evaluation of left ventricular function and volumes in patients with ischaemic cardiomyopathy: Gated singlephoton emission computed tomography versus two-dimensional echocardiography. Eur J Nucl Med 2001;28:1610-5. 
5. van der Wall EE, Vliegen HW, de Roos A, Bruschke AV. Magnetic resonance imaging in coronary artery disease. Circulation 1995;92:2723-39.

6. Roberts WT, Bax JJ, Davies LC. Cardiac CT and CT coronary angiography: Technology and application. Heart 2008;94:781-92.

7. Dirksen MS, Bax JJ, de Roos A, Jukema JW, van der Geest RJ, Geleijns K, et al. Usefulness of dynamic multislice computed tomography of left ventricular function in unstable angina pectoris and comparison with echocardiography. Am J Cardiol 2002;90: 1157-60.

8. Schuijf JD, Bax JJ, Salm LP, Jukema JW, Lamb HJ, van der Wall EE, et al. Noninvasive coronary imaging and assessment of left ventricular function using 16-slice computed tomography. Am J Cardiol 2005;95:571-4.

9. Kim TH, Hur J, Kim SJ, Kim HS, Choi BW, Choe KO, et al. Twophase reconstruction for the assessment of left ventricular volume and function using retrospective ECG-gated MDCT: Comparison with echocardiography. AJR Am J Roentgenol 2005;185:319-25.

10. Salm LP, Schuijf JD, de Roos A, Lamb HJ, Vliegen HW, Jukema $\mathrm{JW}$, et al. Global and regional left ventricular function assessment with 16-detector row CT: Comparison with echocardiography and cardiovascular magnetic resonance. Eur J Echocardiogr 2006;7: 308-14.

11. Schuijf JD, Bax JJ, Jukema JW, Lamb HJ, Salm LP, de Roos A, et al. Assessment of left ventricular volumes and ejection fraction with 16-slice multi-slice computed tomography; comparison with 2D-echocardiography. Int J Cardiol 2007;116:201-5.

12. Henneman MM, Schuijf JD, Jukema JW, Holman ER, Lamb HJ, de Roos A, et al. Assessment of global and regional left ventricular function and volumes with 64-slice MSCT: A comparison with 2D echocardiography. J Nucl Cardiol 2006;13:480-7.

13. Wu YW, Tadamura E, Yamamuro M, Kanao S, Okayama S, Ozasa $\mathrm{N}$, et al. Estimation of global and regional cardiac function using 64-slice computed tomography: A comparison study with echocardiography, gated-SPECT and cardiovascular magnetic resonance. Int J Cardiol 2008;128:69-76.
14. White HD, Norris RM, Brown MA, Brandt PW, Whitlock RM, Wild CJ. Left ventricular end-systolic volume as the major determinant of survival after recovery from myocardial infarction. Circulation 1987;76:44-51.

15. Valentin J. Managing patient dose in multi-detector computed tomography(MDCT). ICRP Publication 102. Ann ICRP 2007;37: 1-79, iii

16. Schiller NB, Shah PM, Crawford M, DeMaria A, Devereux R, Feigenbaum $\mathrm{H}$, et al. Recommendations for quantitation of the left ventricle by two-dimensional echocardiography. American Society of Echocardiography Committee on Standards, Subcommittee on Quantitation of Two-Dimensional Echocardiograms. J Am Soc Echocardiogr 1989;2:358-67.

17. Yamamuro M, Tadamura E, Kubo S, Toyoda H, Nishina T, Ohba $\mathrm{M}$, et al. Cardiac functional analysis with multi-detector row $\mathrm{CT}$ and segmental reconstruction algorithm: Comparison with echocardiography, SPECT, and MR imaging. Radiology 2005;234: 381-90.

18. Higgins CB. Which standard has the gold? J Am Coll Cardiol 1992;19:1608-9.

19. Dewey M, Muller M, Eddicks S, Schnapauff D, Teige F, Rutsch W, et al. Evaluation of global and regional left ventricular function with 16-slice computed tomography, biplane cineventriculography, and two-dimensional transthoracic echocardiography: Comparison with magnetic resonance imaging. J Am Coll Cardiol 2006;48: 2034-44.

20. Sugeng L, Mor-Avi V, Weinert L, Niel J, Ebner C, SteringerMascherbauer R, et al. Quantitative assessment of left ventricular size and function: Side-by-side comparison of real-time threedimensional echocardiography and computed tomography with magnetic resonance reference. Circulation 2006;114:654-61.

21. Schlosser T, Mohrs OK, Magedanz A, Voigtlander T, Schmermund A, Barkhausen J. Assessment of left ventricular function and mass in patients undergoing computed tomography $(\mathrm{CT})$ coronary angiography using 64-detector-row CT: Comparison to magnetic resonance imaging. Acta Radiol 2007;48:30-5. 